\title{
Assessment of needle stick injuries among healthcare workers: A cross-sectional study from Kakiri military and SOS hospitals, Uganda
}

\author{
Robert Basaza ${ }^{1,2}$, Otieno Emmanuel ${ }^{2}$, Christopher Keith Haddock*3 \\ ${ }^{1}$ Uganda Christian University, Mukono, Uganda \\ ${ }^{2}$ Gudie University Project, Uganda \\ ${ }^{3}$ NDRI-USA, Leawood, KS, USA
}

Received: June 12, 2021

Accepted: October 29, 2021

Online Published: December 7, 2021

DOI: $10.5430 /$ ijh.v8n1p10

URL: https://doi.org/10.5430/ijh.v8n1p10

\begin{abstract}
The Ugandan military medical services work together with the civilian public health system to deliver quality healthcare. This Partnership is the mainstay of health service delivery in Uganda. The burden of needle stick injuries (NSIs) is increasing in Uganda's larger health industry; however, data on needle stick injury in military and public health facilities is lacking. No published data exist on comparative studies for a mix of facilities both military and civilian health settings. This study represents the first time this issue has been studied in a military or public health hospital in Uganda. A hospital-based, cross-sectional study was conducted in July 2018 to September 2019 in Kakiri Military and SOS Hospitals in Uganda using a structured questionnaire. Respondents were purposively selected based on the objectives of study, occupation status and department $(\mathrm{N}=310)$. The overall prevalence of NSIs among respondents was $27.2 \%$ and prevalence rates for the two facilities was nearly identical. The largest percentage of NSIs occurred during drawing venous blood samples (49.4\%). Significant predictors of NSI were gender, occupational status, age, poor knowledge on prevention and post exposure of NSI, and less professional experience. Infection control practices were lacking in both selected health facilities. Over a quarter of HCWs in Uganda reported NSIs, which places them at significant health risk. Fostering the practice of universal precautions, best infection control practices and training of healthcare workers on bio-safety measures can reduce the prevalence of NSIs.
\end{abstract}

Key Words: Needle stick injuries, Healthcare workers, Military, Uganda

\section{INTRODUCTION}

\subsection{Ugandan healthcare system}

The healthcare system of Uganda is mixed with the largest proportion of healthcare $(71 \%)$ provided by the public health sector while non-state health entities (for-profit and not-for profit providers at $9 \%$ and $20 \%$ respectively) provide the remaining. ${ }^{[1,2]}$ The country has a total of 6,929 health facilities and a workforce of 39,000 operate the health sector while burdened with a $27 \%$ net vacancy rate. ${ }^{[3,4]}$ Uganda's health sector has experienced tremendous challenges delivering care due to political anarchy, ethnic conflicts, civil wars, and military crises in the Great Lakes Region of Africa. Uganda's healthcare system ranked 149th out of 191 countries in the world by WHO and spends only $7.4 \%$ of its GDP on healthcare. ${ }^{[5,6]}$ Uganda's per capita health expenditure is USD \$51 which far below the international threshold USD

*Correspondence: Christopher Keith Haddock; Email: keithhaddock@ hopehri.com; Address: 1920 West 143rd Street, Leawood, KS 66224, USA. 
\$90 and Uganda's Health Sector Development Plan target of USD \$97. ${ }^{[7]}$ Furthermore, Uganda is the only country in East African region without any form of national universal insurance coverage. ${ }^{[8]}$ Further straining the healthcare system, Uganda is the largest host of refugees in Africa and third in the world. ${ }^{[9]}$

\subsection{The challenge of needle stick injuries}

Globally, needle stick injuries (NSIs) are among the most serious hazards among healthcare workers (HCWs) with more than two million occurring annually. ${ }^{[10]}$ It's estimated that globally and in Africa around $44.5 \%$ and $41.7 \%$ of HCWs respectively sustain NSIs. ${ }^{[10]}$ However, more than $90 \%$ of NSIs occur in low- and middle-income countries (LMICs) with sub-Saharan Africa's prevalence ranging from $28.8 \%$ to $68 \% .^{[11,12]}$ The prevalence rate is highest at $58 \%$ in Kenya and $52.9 \%$ in Tanzania. ${ }^{[13,14]}$ NSIs have long plagued the Uganda healthcare system, where the ongoing epidemics of HIV/AIDS and other blood borne infections make these injuries particularly problematic. In the most recent national data (2003), the incidence rate of NSI in Uganda was estimated at $44 \%$ of healthcare workers per year. ${ }^{[15]}$ More recent data on NSI in Uganda is scanty and based on small samples of providers. Hulem surveyed 79 nursing students in a rural Ugandan hospital and found that $25.3 \%$ had experienced NSI with $50 \%$ of those from sources potentially infected with HIV. ${ }^{[16]}$ In a survey of healthcare workers in the Gulu district in Uganda, Odongkara and colleagues discovered that $46 \%$ had been exposed to potentially infectious body fluids, with NSI accounting for $27.7 \%$ of exposures. ${ }^{[17]}$ Otherwise, little empirical data exists for recent NSI prevalence or risk factors in Uganda.

\subsection{Barriers to addressing needle stick injuries in Uganda}

Uganda also faces difficulties with addressing NSIs in its healthcare workforce. Structural barriers include overworked staff due to the shortage of HCWs and a dearth of training on preventing NSI. ${ }^{[18]}$ In addition to gaps in knowledge and skills of healthcare workers, Uganda is at higher risk of NSI due to inadequate infection and prevention control measures. ${ }^{[19,20]}$ Despite that, Uganda developed its own policies and programs in non-communicable disease (NCD) prevention and control (including prevention of NSIs) and passed the Occupational and Safety Health legislation in 2006. ${ }^{[18,21]}$ Similar to many other LMICs, there is lax implementation of policy interventions and enforcement standards to protect healthcare workers from exposure and reduction of NSIs and unsafe infection control practices are common. ${ }^{[22,23]}$ This supports the need for ongoing research into prevalence and risk factors for NSIs among sectors of the Ugandan health-

Published by Sciedu Press care system.

\subsection{The purpose of this study}

Because of the need to provide adequate healthcare care for military personnel, since 1986 provision of care to military personnel from the Chieftaincy of military medical services within the Uganda Peoples Defense Forces (UPDF) was established. Included in the public sector are UPDF medical services which are considered part of the public sector of the Uganda healthcare system. Unfortunately, no study to date has been conducted on NSIs in Uganda's military health service.

\section{Methodology}

\subsection{Study aim}

The aim of the study was to determine prevalence and risk factors of needle stick injuries among healthcare worker in Kakiri military and SOS hospital in Uganda who have at least 6 months of professional experience. Military personnel often receive care from the SOS Hospital in addition to the Kakiri Military Hospital.

\subsection{Setting}

Uganda is a landlocked country in East Africa. There are currently 146 districts and 2,184 Sub-Counties (the layer below the districts); there is no regional government. This study was conducted in the Kakiri sub-County located at Wakiso District in the central area of the country about 26.3 $\mathrm{km}$ northwest of Kampala, the capital city of Uganda. Kakiri sub-County has a population of $39,137 . .^{[24]}$ The study was done from July to September 2018 at the Kakiri Military Hospital and the SOS Hospital (SOS Hermann Gmeiner Hospital). The Kakiri Military Hospital is located within the $1^{\text {st }}$ Division Military Barracks of the UPDF while the SOS hospital is situated at SOS Children's Village Uganda, a Non-Government Organization (NGO).

\subsection{Inclusion/exclusion criteria}

Military and civilian healthcare workers, with a minimum employment experience of six months at Kakiri Military and SOS hospitals who consented to participate in the study. Healthcare workers recruited were staff in hospitals (doctors, nurses, laboratory technologists, dentists, and ancillary staff) who have contact with needles, syringes and sharp instruments due to their responsibilities. The participants were asked to report NSIs suffered over 12 months' period of time from the day the study was conducted retrospectively. Those who did not consent to participate in the study, those on leave, and those mainly performing administrative duties were excluded from the study. 


\subsection{Data collection procedures}

A mixed method approach was employed, which included a review of incident reports of NSIs at each hospital and a self-report questionnaire completed by healthcare worker participants. A structured, pre-tested questionnaire was used in this study. Items were adapted from previous studies of NSIs among health care workers. ${ }^{[15,25,26]}$ Epidemiologists of the chieftaincy of military medical services and infection control provided feedback during the development of the questionnaire and face validity was established. The survey was conducted in English. The questionnaire was pilot tested with 20 healthcare workers at Masaka Mechanized Battalion near Kakiri Military Barracks prior to execution with study volunteers.

\subsection{Sampling methods}

A stratified random sampling was utilized to select the respondents from the two hospitals. First, the total number of healthcare workers was identified. Respondents' lists were used as sampling framework to select a proportionate random sample of eligible respondents drawn by occupation group (stratum) to participate in survey. The occupational strata were doctors, nurses, laboratory technicians, and support staff.

\subsection{Operational definition}

A needle stick injury was defined as $a$ wound caused by $a$ needle point or other penetrating devices.

\subsection{Statistical modeling}

Data was analyzed using Statistical Package for the Social Sciences (SPSS) version 16. Categorical variables are presented as percentages. Logistic regression modeling was used to evaluate risk factors of NSI. The chi-square test was used to assess significance of the relationship between the variables. A Pearson Correlation Matrix was used to assess multicollinearity among the predictors. $p$ values $<.05$ were used to define statistical significance.

Table 1. Demographic characteristics of respondents

\begin{tabular}{|c|c|c|c|c|}
\hline Characteristics & KMH (f) & SOS H (f) & Overall (f) & Percent (\%) \\
\hline \multicolumn{5}{|l|}{ Age (years) } \\
\hline 40 and above & 40 & 13 & 53 & 18.7 \\
\hline $35-39$ & 58 & 20 & 78 & 27.6 \\
\hline $30-34$ & 83 & 16 & 99 & 34.9 \\
\hline $29-25$ & 42 & 9 & 51 & 18.1 \\
\hline $20-24$ & 1 & 1 & 2 & 0.7 \\
\hline \multicolumn{5}{|l|}{ Gender } \\
\hline Male & 85 & 16 & 101 & 35.7 \\
\hline Female & 139 & 43 & 182 & 64.3 \\
\hline \multicolumn{5}{|l|}{ Job Category } \\
\hline Doctors & 10 & 5 & 15 & 5.3 \\
\hline Nurses & 122 & 28 & 150 & 53.0 \\
\hline Laboratory Tech & 13 & 4 & 17 & 6.1 \\
\hline Ancillary Staff & 79 & 22 & 101 & 35.6 \\
\hline \multicolumn{5}{|l|}{ Years of Experience } \\
\hline $1-5$ & 28 & 20 & 48 & 17.0 \\
\hline $6-10$ & 82 & 11 & 93 & 33.0 \\
\hline $11-15$ & 55 & 7 & 62 & 22.0 \\
\hline $16-20$ & 40 & 9 & 49 & 17.0 \\
\hline$>20$ & 19 & 12 & 31 & 11.0 \\
\hline \multicolumn{5}{|l|}{ Shift Schedule } \\
\hline Morning (6 am-1 pm) & 79 & 21 & 100 & 35.3 \\
\hline Afternoon (2 pm-6 pm) & 67 & 17 & 84 & 30.0 \\
\hline Evening (7 pm-9 pm) & 30 & 9 & 39 & 13.7 \\
\hline Night (10 pm-5 am) & 48 & 12 & 60 & 21.0 \\
\hline
\end{tabular}

Note. KMH = Kakiri Military Hospital, SOS H = SOS Hermann Gmeiner Hospital, $\mathrm{f}$ = frequency 


\section{RESUlts}

\subsection{Response rate and demographic characteristics}

All the 283 HCWs recruited agreed to participate, giving a response rate of $100 \%$. Table 1 shows the demographic characteristics of the respondents by age, gender, job categories, years of experience and shift schedule. The participants were within age range from 22 to 59 years and mean $( \pm \mathrm{SD}) 33.56$ \pm 6.41 years. The majority of participants were within age range from 30 to 34 years (57.7\%). Among the 283 respondents, a majority (53\%) were nurses, followed by ancillary staff $(35.6 \%)$, laboratory technologists $(6.1 \%)$ and doctors $(5.3 \%)$.

\subsection{Prevalence and characteristics of needle stick in- juries}

The overall prevalence of needle stick injuries reported among HCWs in the previous 12 months was $27.2 \%$ (N $=77$ ). The prevalence of NSIs for each hospital was nearly identical (Kakiri Military Hospitals $27.2 \%$ vs. SOS Hospital $27.1 \%$ ); thus, characteristics and risk factors for NSIs were evaluated for all participants. Table 2 provides characteristics of NSIs among HCWs. The majority of NSIs was percutaneous injuries $(57.1 \%)$ and the most common injured anatomic body site was the fingertips at $79.2 \%$. The NSIs occurred mostly during drawing venous blood samples (49.4\%) and was precipitated mostly by HCWs error (51.9\%).

Table 2. Needle stick injury characteristics

\begin{tabular}{lll}
\hline Exposure & Number $(\mathbf{n}=\mathbf{7 7}$ total) & Percent \\
\hline Types of NSI & 44 & 57.1 \\
$\quad$ Percutaneous & 13 & 16.9 \\
Laceration & 18 & 23.4 \\
Exposure to Body fluids & 2 & 2.6 \\
$\quad$ Exposure to patients' blood & & \\
Body Site of Exposure & 61 & 79.2 \\
Fingertips & 11 & 14.3 \\
Hand & 5 & 6.5 \\
Arms & & \\
Type of Procedure Involved & 38 & 49.4 \\
Drawing venous blood samples & 16 & 20.8 \\
Setting up IV line & 3 & 3.8 \\
Conduction of delivery & 13 & 16.9 \\
Surgical operation & 4 & 5.2 \\
Injection administration & 1 & 1.3 \\
Handling cadaver in mortuary & 2 & 2.6 \\
Environmental cleaning & & \\
Reasons for Injury & 40 & 51.9 \\
Health care worker error & 30 & 39 \\
Patient caused & 7 & 9.1 \\
Accidental injury by a colleague & & \\
Reported Incident & 18 & 23.4 \\
Yes & 59 & 76.6 \\
No & & \\
\hline
\end{tabular}

\subsection{Reported NSI by occupation}

The reported NSI among healthcare occupations are presented in Table 3. Despite KMH having greater number of participants in the study who suffered NSI, only $7.8 \%$ (n $=6 / 61$ ) reported NSI. On the contrary, the HCWs of SOS reported the highest rate which was twice as much as of KMH: $15.6 \%(n=12 / 16)$. About three quarters of participants $(76.7 \%, \mathrm{n}=59 / 77)$ never reported after sustaining an
NSI. The female participants had the highest rate $(57.6 \%, \mathrm{n}$ $=34 / 59$ ) of "hiding" an NSI. On the other hand, all doctors did not "hide" (i.e., not report) an NSI. However, nurses hid more NSI $(76.2 \%, \mathrm{n}=45 / 59)$ followed by the ancillary staff at $22 \%(n=13 / 59)$. Surprisingly, the most educated participants with a University degree level of education hid NSI $(35.6 \%, n=21 / 59)$, followed by diploma, certificate and the least those with ordinary level education $(5 \%, n=3 / 59)$. 
Table 3. Reported NSI among occupation

\begin{tabular}{|c|c|c|c|c|c|}
\hline \multirow{2}{*}{ Hospital } & \multicolumn{4}{|c|}{ Occupation } & \multirow{2}{*}{ Total } \\
\hline & Anc. Staff & Doctor & Lab Tech & Nurses & \\
\hline $\mathrm{N}$ & 101 & 15 & 17 & 150 & 283 \\
\hline \multicolumn{6}{|l|}{ KMH } \\
\hline Reported & 10 & 0 & 1 & 44 & 55 \\
\hline Not reported & 3 & 1 & 2 & 0 & 6 \\
\hline \multicolumn{6}{|l|}{ sos } \\
\hline Reported & 3 & 0 & 0 & 1 & 4 \\
\hline Not reported & 1 & 0 & 1 & 10 & 12 \\
\hline \multicolumn{6}{|l|}{ Overall } \\
\hline Reported & 13 & 0 & 1 & 45 & 59 \\
\hline Not reported & 4 & 1 & 3 & 10 & 18 \\
\hline
\end{tabular}

Table 4. Factors associated with needle stick injury

\begin{tabular}{|c|c|c|c|c|c|}
\hline Variable & NSI Yes & NSI No & Prevalence (\%) & Odds ratio (95\% CI) & $p$-value \\
\hline \multicolumn{6}{|l|}{ Age (years) } \\
\hline $20-24(n=4)$ & 1 & 3 & 25 & Ref & \\
\hline $25-29(\mathrm{n}=28)$ & 17 & 11 & 60.7 & $0.21(0.01-2.34)$ & .2 \\
\hline $30-34(n=109)$ & 26 & 83 & 23.8 & $1.06(0.10-10.67)$ & .95 \\
\hline $35-39(\mathrm{n}=89)$ & 12 & 77 & 13.5 & $2.13(0.20-22.28)$ & .52 \\
\hline$>40(\mathrm{n}=53)$ & 21 & 32 & 39.6 & $0.50(0.04-5.21)$ & .6 \\
\hline \multicolumn{6}{|l|}{ Gender } \\
\hline Female $(\mathrm{n}=182)$ & 46 & 136 & 25.2 & & \\
\hline Male $(\mathrm{n}=101)$ & 31 & 70 & 30.7 & $0.76(0.44-1.3)$ & .32 \\
\hline \multicolumn{6}{|l|}{ Work experience (years) } \\
\hline $1-5(n=45)$ & 15 & 30 & 33.3 & Ref & \\
\hline $6-10(n=63)$ & 26 & 37 & 41.2 & $0.71(0.32-1.57)$ & .4 \\
\hline $11-15(\mathrm{n}=60)$ & 20 & 40 & 33.3 & $1.00(0.44-2.27)$ & 1.0 \\
\hline $16-20(\mathrm{n}=48)$ & 8 & 40 & 16.7 & $2.50(0.93-6.66)$ & .06 \\
\hline$>20(\mathrm{n}=67)$ & 8 & 59 & 11.9 & $3.68(1.40-9.67)$ & .008 \\
\hline \multicolumn{6}{|l|}{ Work Shift } \\
\hline Morning: 6am-1pm ( $\mathrm{n}=127)$ & 47 & 80 & 37.0 & Ref & \\
\hline Afternoon: 2pm-6pm ( $\mathrm{n}=73)$ & 13 & 60 & 17.8 & $2.7(1.34-5.45)$ & .005 \\
\hline Evening: 7pm-9pm ( $\mathrm{n}=49)$ & 7 & 42 & 14.3 & $3.5(1.46-8.47)$ & .004 \\
\hline Night: 10pm-5am ( $\mathrm{n}=34)$ & 10 & 24 & 29.4 & $1.4(0.62-3.2)$ & .41 \\
\hline \multicolumn{6}{|l|}{ PPE Availability } \\
\hline Available $(\mathrm{n}=108)$ & 18 & 90 & 16.7 & & \\
\hline Not Available $(n=175)$ & 59 & 116 & 33.7 & $0.39(0.21-0.71)$ & .002 \\
\hline \multicolumn{6}{|l|}{ Use of PPE } \\
\hline Yes $(n=139)$ & 53 & 86 & 38.1 & Ref & \\
\hline No $(n=144)$ & 24 & 120 & 16.7 & $3.08(1.76-5.37)$ & .0001 \\
\hline
\end{tabular}

Note. KMH: Kakiri Military Hospital, SOS H: SOS Hospital, NSI: Needle Stick Injury, PPE: Personal Protective Equipment 


\subsection{Factors associated with needle stick injury}

Factors associated with NSI are presented in Table 4. Female HCWs accounted for the majority of all NSI (59.7\% vs. $40.3 \%$ ). However, the rate of NSI was higher in males at $30.7 \%(\mathrm{n}=31 / 101)$ compared to females $(25.7 \%$; $\mathrm{n}=$ 46/182). This is due to the fact that a larger percentage of HCWs are female. Participants aged 25 to 29 years suffered greatly NSI followed by those above 40 years at $60.7 \%$ and $39.6 \%$ respectively. The HCWs with 16 to 20 years of experience were the least likely to sustain a NSI (16.7\%) while those with 11 to 15 years of experience had a NSI rate of $33.3 \%$. However, only those with experience of above 20 years were the least likely to suffer an NSI at $11.9 \%$. To the contrary, almost half of the HCWs with 6 to 10 years working experience highly sustained NSI at $31.7 \%$. The HCWs in the morning shift, had the highest rates to experience NSI ( 6 am to $1 \mathrm{pm} ; 37.0 \%$ ), followed by night ( $10 \mathrm{pm}$ to $5 \mathrm{am}$; $29.4 \%$ ) shifts, afternoon ( $2 \mathrm{pm}$ to $6 \mathrm{pm} ; 17.8 \%)$ and evening (7 pm to $9 \mathrm{pm} ; 14.3 \%$ ) had the lowest. Only about a quarter (23.4\%) of those who experienced a NSI reported it to their hospital. The NSI was much higher among those who used PPE at $38.1 \%$ versus those who didn't at $16.7 \%$, likely due to a difference in job tasks.

The factors associated with frequency of NSIs are presented in Table 4. Among the factors tested, work experience of more than 20 years (OR 3.68, 95\% C.I: 1.40-9.67, $p=.008$ ); work shifts of evening hours from $7 \mathrm{pm}$ to $9 \mathrm{pm}$ (OR 3.5, 95\% C.I: $1.46-8.47, p=.004)$ and afternoon shifts from 2 pm to 6 pm (OR 2.7, 95\% C.I: 1.34-5.45, $p=.005)$; PPE availability (OR $0.390,95 \%$ C.I: $21-0.71, p=.002$ ) and use of PPE (OR 3.08, 95\% C.I: 1.76-5.37, $p=.0001$ ) were significant predictors. A HCW with experience of more than 20 years were nearly 3.7 times more likely to sustain NSI than a $\mathrm{HCW}$ in the 11-20 year category. The HCWs working in the evening hours from $7 \mathrm{pm}$ to $9 \mathrm{pm}$ were 3.5 times as likely to sustain NSI compared to those working the morning hours. NSI was least likely to occur during the morning and night shifts. HCW who had PPE available were nearly 2.6 times less likely to sustain a needle stick injury. Factors that did not significantly affect the risk of NSIs were: age, gender and work experience of less than 20 years, work shift (morning 6 am to $1 \mathrm{pm}$ and night $10 \mathrm{pm}$ to $5 \mathrm{am}$ ).

\section{Discussion}

The health and wellbeing of workforce is fundamental to the achievement of the organization's current goals and future ambitions in both civil and military settings. More so, safety is a priority in the military. Nonetheless, needle-stick injury is still a silent challenge in Uganda's health system. This study reported NSIs suffered by HCWs in the 12 months pre-

Published by Sciedu Press ceding this survey. Nearly $27.2 \%$ of the sample experienced NSI over a period of this time. This rate was considerably lower than the national prevalence rate at $46 \%$; however, the most recent national data was from 2003. ${ }^{[15]}$ Thus, this study of two hospitals suggests there is a $27.2 \%$ prevalence of NSI in Uganda; however, no national data is available. This is also slightly lower than the findings in other similar studies in Ethiopia, Malaysia and China which is $29.3 \%, 27.9 \%$ and $27.5 \%$ respectively. ${ }^{[12,26,27]}$ In contrast, rates of NSI were higher than that found in Australia (17.7\%) and much lower than findings from South Korea, Iran and Pakistan at $74 \%, 42.5 \%$ and $94 \%$ respectively. ${ }^{[28,29]}$ The relatively low prevalence rate of NSI in our sample (27.2\%) does not necessarily reflect fewer injuries and good adherence to safety guidelines given the lack of reporting systems in Uganda. Developed countries like Germany and South Korea with robust reporting systems, standard operating procedures and accurate injury surveys have reported higher rates of NSI at $31.4 \%$ and $74 \%$ indicate that NSI is a serious challenge to healthcare industry. ${ }^{[29,30]}$ Thus, there may be significant underreporting of NSIs among HCWs in Uganda compared to nations with higher reported rates. Females accounted for the majority of NSI (59.7\%), the prevalence of NSI was higher in males compared with females. This is not surprising given the majority of $\mathrm{HCW}$ are female. This finding aligns with previous studies. ${ }^{[10,29]}$ It is not clear why males were more likely to experience NSI. Given that most nurses were female, perhaps nurses do a better job sensitizing their workforce to the risks of NSI and how to reduce their prevalence. Another possibility is that the females deployed for this tasks could be more experienced than their male counterparts since the majority of HCWs at this level are predominantly females. Another likelihood is that female HCWs collaborate and expedite team work better than their male counterparts thus reducing chances of NSIs. Interestingly, $80 \%(n=44 / 55)$ of the nurses were from KMH. This further indicates the high burden of workload that comprise of "double tragedy" in which both military and public healthcare workplaces are stressful and demand sufficient attention to avoid errors. When the prevalence of NSI is stratified by gender, and the male subgroup $(30.7 \%, \mathrm{n}=31 / 101)$ and female subgroup $(25.7 \%, n=46 / 182)$ are compared, the risk of NSI is higher for males. This is given that, women represent a much higher percentage of the HCW workforce $(64.3 \%)$. This finding suggests that men probably had negative attitude to occupational health and safety. More so, women are more likely to experience stress at work than men due to gender inequality, often poor remuneration and burden of familial roles thus, more exposed to occupational risks. ${ }^{[31,32]}$ This contradicts studies done in USA where males were 4.5 times and in 
Nigeria were 10 times more likely to be injured than female HCWs. ${ }^{[23,30]}$ Similar to studies conducted in India at $70 \%$ and Iran at $57 \%$, in this study the morning shift indicated the highest rate of NSI at $61 \% .^{[33,34]}$ This might be due to the small number of HCWs attending to the increased patient load at this period than any other shift. One study conducted in Ethiopia, in contrast, found that NSIs were most likely to occur on the night shift. ${ }^{[28]}$

The NSIs mostly occurred during drawing venous blood samples accounting for $49.4 \%$ of all incidents. ${ }^{[35,36]}$ However, several studies done indicate that most of the NSI occur during recapping of needles and injection. ${ }^{[23,37]}$ Kargin and Akyol $^{[38]}$ indicated in a study conducted in 3 hospitals in Turkey NSI were mainly attributed by injection needles at $35.8 \%$. In another cross-sectional study done by Joukar et al. in 8 teaching hospitals of Rasht in $\operatorname{Iran}^{[39]}$ the NSI were mainly due to recapping at $37.1 \%$.

The underreporting of NSI by HCWs is documented in several studies ranging from $22 \%$ to $99 \%$. $^{[22,27]}$ The rate of reporting of NSI was $23.4 \%$ in this study, which is low compared with several studies. ${ }^{[29,37]}$ Furthermore, Bowman and Bohnker showed that underreporting of NSI was more prevalent in the civil health system than US military facilities. ${ }^{[40]}$ This is in contrast with the findings of this study where underreporting is high in military than the civil setting in spite of similar NSI prevalence in the two hospitals. This could be due to most administrators in military health facilities being service men who do not have a healthcare background and as a result control measures are not in place and NSI reporting is given less attention compared to security.

Many reasons cited for underreporting were perception of low-risk infection, ignorance that it should be reported, time constraint and incident reporting protocols. ${ }^{[28]}$ In contrast, in a study done by Maniar et al. ${ }^{[22]}$ indicated that there was no underreporting among healthcare workers. Unfortunately, in Uganda HCWs do not consider incident reporting protocol with immense gravity. In this study, reasons adduced for underreporting were perception of low risk infection transmission at $68.9 \%$. More so, nurses who are female and had higher education level are more likely to "hide" an NSI than the any other cadres. This could be attributed to lack of gender equity and lower cadre status in male dominated institutions of military and healthcare.

Although this study has added depth and breadth to the picture of needle stick injury among healthcare workers it was cross-sectional in design. Hence, variables identified as being significantly associated with NSI may not be assumed to be predictive. A more accurate estimation of the number of and the types of NSI among healthcare workers would be to validate self-reports with administrative records, which was not possible for this study given the lack of an adequate reporting system in Uganda. This study only reported NSI in the 12 months preceding this survey falling short of providing NSI suffered by HCWs in their career service over a period of time in totality. Given this study is based on selfreporting from HCWs, there is a likelihood of underreporting due to social desirability and recall bias respectively.

\section{Conclusion}

Health and safety coupled with administrative controls will always remain a top priority in healthcare industry. The implementation of PPE and development of institutional policies to achieve this goal more effectively is of obvious benefit to Uganda's health system including continuous professional development, increasing staff levels and recognition of the champions of safety. The risk factors associated with needle stick injury identified in the models proposed, including younger age, morning and night work shifts, and lack of training on safety should inform future efforts to reduce NSIs in Uganda. Considering the health and legal concerns from NSIs, there is a need to evaluate work safety policies, infection control practices and universal precaution tools in Ugandan health facilities. There was no qualitative data collection which could have enriched the study findings. The study was conducted at 2 hospitals in Uganda, so the generalizability of the results to all hospitals in Uganda is unknown.

Furthermore, the study did not explore NSIs among HCWs in their entire career service. Finally, systems to track and intervene on NSIs is sorely needed in countries like Uganda.

\section{ACKNOWLEDGEMENTS}

The authors are grateful to all the research respondents.

\section{CONFlicts of InTEREST Disclosure}

The authors declare no conflicts of interest.

\section{REFERENCES}

[1] Whyle EB, Olivier J. Models of public-private engagement for health services delivery and financing in Southern Africa: a systematic review. Health Policy Plan. 2016 Dec; 31(10): 1515-1529.
PMid:27296061. https://doi.org/10.1093/heapol/czw075

[2] Okwero P, Tandon A, Sparkes S, et al. Fiscal Space for Health in Uganda. World Bank Working Paper; No. 186. Africa Human Development Series. World Bank. C) World Bank. 2010. https : 
//doi.org/10.1596/978-0-8213-8290-5

[3] National health facility master list 2018 - Ministry of Health, health.go.ug > sites > default > files.

[4] Government of Uganda. Human Resources for Health Audit Report. 2017. library.health.go.ug > sites > default > files > Human Reso...PDF. Accessed 11 Jun. 2021.

[5] Ministry of Health. Uganda Health Accounts - National Health Expenditure, 2016/17-2017/18; Kampala, Uganda: Ministry of Health; library.health.go.ug. Accessed 9 Jun. 2021.

[6] World Health Organization. The World health report: 2000: Health systems: improving performance. World Health Organization. Available from: https://apps.who.int/iris/handle/10665/422 81 Accessed 2 Jun 2021.

[7] Stenberg K, Hanssen O, Edejer TT, et al. Financing transformative health systems towards achievement of the health Sustainable Development Goals: a model for projected resource needs in 67 low-income and middle-income countries. Lancet Glob Heal. 2017; 5(9): e875-87. https : //doi.org/10.1016/S2214-109X (17) 3 0263-2

[8] Basaza RK, O’Connell TS, Chapčáková I. Players and processes behind the national health insurance scheme: a case study of Uganda. BMC Health Serv Res. 2013; 13: 357. PMid:24053551. https://doi.org/10.1186/1472-6963-13-357

[9] Ahimbisibwe F. Uganda and the Refugee Problem: Challenges and Opportunities. African Journal of Political Science and International Relations. 2019; 13(5): 62-72. https ://doi.org/10.5897/AJPS IR2018.1101

[10] Bouya S, Balouchi A, Rafiemanesh H, et al. Global Prevalence and Device Related Causes of Needle Stick Injuries among Health Care Workers: A Systematic Review and Meta-Analysis. Annals of Global Health. 2020; 86(1): 35. PMid:32346521. https://doi.org/10 .5334 /aogh. 2698

[11] Yazie TD, Chufa KA, Tebeje MG. Prevalence of needlestick injury among healthcare workers in Ethiopia: a systematic review and metaanalysis. Environ Health Prev Med. 2019; 24: 52. PMid:31409284. https://doi.org/10.1186/s12199-019-0807-7

[12] Amira CO, Awobusuyi JO. Needle-stick injury among health care workers in hemodialysis units in Nigeria: a multi-center study. Int $\mathbf{J}$ Occup Environ Med. 2014; 5: 1-8.

[13] Ministry of Health Kenya. National policy on injection safety and medical waste management. MOH, Nairobi, Kenya 2007.

[14] Manyele SV, Ngonyani HA, Eliakimu E. The status of occupational safety among health service providers in hospitals in Tanzania. Tanzan J Health Res. 2008; 10(3): 159-65. PMid:19024341. https://doi.org/10.4314/thrb.v10i3.14356

[15] Ministry of Health (MOH) [Uganda]: National health care waste management plan 2009/10 - 2011/2012. Accessed January 2020

[16] Hulme P. Incidence of needlestick injuries among Ugandan student nurses in a rural hospital. Rural Remote Health. 2009; 9(2): 1185. PMid:19466873. https : //doi .org/10.22605/RRH1185

[17] Odongkara BM, Mulongo G, Mwetwale C, et al. Prevalence of occupational exposure to HIV among health workers in Northern Uganda. Int J Risk Saf Med. 2012; 24(2): 103-13. PMid:22751192. https://doi.org/10.3233/JRS-2012-0563

[18] Rogers HE, Akiteng AR, Mutungi G, et al. Capacity of Ugandan public sector health facilities to prevent and control non-communicable diseases: an assessment based upon WHO-PEN standards. BMC Health Serv Res. 2018; 18: 606. PMid:30081898. https ://doi .or $\mathrm{g} / 10.1186 / \mathrm{s} 12913-018-3426-\mathrm{x}$

[19] Baine SO, Kasangaki A. A scoping study on task shifting; the case of Uganda. BMC Health Serv Res. 2014; 14: 184. PMid:24754917. https : //doi.org/10.1186/1472-6963-14-184
[20] Mill J, Nderitu E, Richter S. Post-exposure prophylaxis among Ugandan nurses: "Accidents do happen". International Journal of Africa Nursing Sciences. 2014; 1. https : //doi.org/10.1016/j.ijan s. 2014.05 .003

[21] Ministry of Health Uganda. Guidelines for Occupational safety and Health including HIV in the Health Services Sector, 2008.

[22] Maniar HH, Tawari AA, Suk M, et al. Percutaneous and mucocutaneous exposure among orthopaedic surgeons: immediate management and compliance with CDC protocol. J Orthop Trauma. 2015; 29(10): e391. PMid:25967855. https ://doi .org/10.1097/BOT . 0000000000000360

[23] Abebe D, Desalegn A, Tenaw G. Occupational exposure to needle stick and sharp injuries and associated factors among healthcare workers in Awi zone, amhara regional state, northwest Ethiopia, 2016. Hindawi Journal of Environmental and Public Health. 2017 PMid:28855920. https : //doi.org/10.1155/2017/2438713

[24] Electoral Commission Statistics. www.ec.or.ug > electoralcommission-statistics Number of Districts in Uganda. Accessed September 2020 .

[25] AlDakhil L, Yenugadhati N, Al-Seraihi O, et al. Prevalence and associated factors for needlestick and sharp injuries (NSIs) among dental assistants in Jeddah, Saudi Arabia. Environ Health Prev Med. 2019; 24: 60. PMid:31601166. https://doi .org/10.1186/s12199-0 19-0815-7

[26] Rampal G, Lekhraj R, Zakaria, et al. Needle Stick and Sharps Injuries and Factors Associated Among Health Care Workers in a Malaysian Hospital. European Journal of Social Sciences. 2010; 13: 354-362.

[27] Cui Z, Zhu J, Zhang X, Wang B, et al. Sharp injuries: a cross sectional study among healthcare workers in a provincial teaching hospital in China. Environmental Health and Preventive Medicine. 2018; 23 : 2. PMid:29316884. https ://doi.org/10.1186/s12199-017-0 691-y

[28] Kebede A, Gerensea H. Prevalence of needle stick injury and its associated factors among nurses working in public hospitals of Dessie town, Northeast Ethiopia, 2016. BMC Res Notes. 2018; 11: 413.

[29] Ghanei GR, Aslani M, Shabani F, et al. Prevalence of needlestick and sharps injuries in the healthcare workers of Iranian hospitals: an updated meta-analysis. Environ Health Prev Med. 2018; 23: 44. PMid:30193569. https://doi.org/10.1186/s12199-018 $-0734-z$

[30] Assen S, Wubshet M, Kifle M, et al. Magnitude and associated factors of needle stick and sharps injuries among health care workers in Dessie City Hospitals, north east Ethiopia. BMC Nurs. 2020; 19: 31. PMid:32336947. https://doi .org/10.1186/s12912-0 20-00422-0

[31] Travasso SM, Rajaraman D, Heymann SJ. A qualitative study of factors affecting mental health amongst low-income working mothers in Bangalore, India. BMC Women's Health. 2014; 14: 22. PMid:24502531. https ://doi.org/10.1186/1472-6874-1 4-22

[32] Nappo N. Job stress and interpersonal relationships cross country evidence from the EU15: a correlation analysis. BMC Public Health. 2020; 20: 1143. PMid:32689996. https://doi.org/10.1186/s1 2889-020-09253-9

[33] Sriram S. Study of needle stick injuries among healthcare providers: Evidence from a teaching hospital in India. J Family Med Prim Care. 2019; 8(2): 599-603. PMid:30984680. https://doi .org/10.410 $3 / j \mathrm{fmpc} \cdot$ jfmpc_454_18

[34] Jahangiri M, Rostamabadi A, Hoboubi N, et al. Needle Stick Injuries and their Related Safety Measures among Nurses in a University Hospital, Shiraz, Iran. Saf Health Work. 2016; 7(1): 72-77. 
PMid:27014494. https://doi.org/10.1016/j.shaw .2015.07 .006

[35] Chalya P, Seni J, Mushi MF, et al. Needle-stick injuries and splash exposures among health-care workers at a tertiary care hospital in north- western Tanzania. Tanzania Journal of Health Research. 2015; 17 .

[36] Ballout RA, Diab B, Harb AC, et al. Use of safety-engineered devices by healthcare workers for intravenous and/or phlebotomy procedures in healthcare settings: a systematic review and metaanalysis. BMC Health Serv Res. 2016; 16: 458. PMid:27581947. https://doi.org/10.1186/s12913-016-1705-y

[37] Garus-Pakowska A, Górajski M. Epidemiology of needlestick and sharp injuries among health care workers based on records from 252 hospitals for the period 2010-2014, Poland. BMC Public Health.
2019; 19: 634. PMid:31126266. https://doi.org/10.1186/s1 2889-019-6996-6

[38] Kargin C, Akyol AD. Needle Stick and Sharp Injuries among Nurses. Glob J Nurs Forensic Stud. 2016; 1: 109. https://doi . org/10.4 172/2572-0899.1000109

[39] Joukar F, Mansour Ghanaei F, Naghipour M, et al. Needlestick Injuries among Healthcare Workers: Why They Do Not Report their Incidence? Iranian Journal of Nursing and Midwifery Research. 2018; 23(5): 382-387. PMid:30186344. https://doi .org/10.4 103/ijnmr. IJNMR_74_17

[40] Wendi B, Bruce K, Bohnker MC. Needle-Stick Epidemiology in Navy Health Care Workers Based on INJTRAK Reports (2001-2002). Military Medicine. 2005; 170(12): 10341036. PMid:16491943. https://doi.org/10.7205/MILMED.170.12.1034 